\title{
Prophase of Spermatocyte I in Oedionychina (Coleoptera) ${ }^{1}$
}

\author{
Niilo Virkki
}

\begin{abstract}
Fleabeetles of the subtribe Oedionychina fall in two phylogenetic categories in relation to the structure of the nuclear envelope, and of the epinuclear material synthesized in the diffuse stage of spermatocyte I. Omophoita shows a plain envelope surrounded by a continuous sheath of epinuclear material, whereas Oedionychus and related genera show a rough envelope with cup-like nuclear sieve complexes, and a discontinuous epinuclear material. The epinuclear material has no part in breaking down the nuclear envelope, which is wrinkled and squashed against the cell wall by aster action. The envelope does not wholly disappear until the prometaphasic congression. Released, empty nuclear sieves form a swarm at the surface of the M I spindle, and can be sometimes recognized still in the M II spindle. No interkinetic nucleus forms.

The unique structure of nuclear envelope of Oedionychus suggests a more advanced evolutionary status as compared with Omophoita, a genus having some karyotypic affinities toward the sister subtribe Disonychina.
\end{abstract}

\section{INTRODUCTION}

The spermatocyte I of Oedionychina fleabeetles grows to dimensions unusual for Coleoptera: about $50 \mu \mathrm{m}$ across. This final size is the result of a large initial size determined by the last, grossly unequal gonial mitosis (12), and by a true growth in the following prophase. In one of the Puerto Rican species, Omophoita cyanipennis F., male meiosis has been studied in living and in fixed condition (11). The epinuclear material synthesized during prophase was found to detach from its position just before PM I, to be collected around the just activated asters at the basal (idiosomal)

\footnotetext{
${ }^{1}$ Manuscript submitted to Editorial Board February 26, 1976.

${ }^{2}$ Cytogenetist, Agricultural Experiment Station, University of Puerto Rico, Mayagüez, Campus, Rı Piedras, P.R.

The author is indebted to Dr. Karl Maramorosch, from the Waksman Institute of Microbiology, Rutgers University, New Brunswick, N. J., U.S.A., for facilities in electron microscopy, to Mrs. Joan Reitz from the same Institute, and to Dr. Michio Kimura from Wakayama Medical College, Japan, for technical guidance. The South American material was collected under support of NSF grants GB 1917 and GB 4522.
} 
region of the cytoplasm. After breakdown of the nuclear envelope, the material seemed to invade the nuclear space, pushing chromosomes to a clump against the opposite cell wall (contraction stage). From there, the congression movements started after one hour, resulting in a bipartite $\mathrm{M}$ I spindle: autosomal bivalents in the center of the cell, the distance sex bivalent laterally at the site of the former clump. Comparison with similar observations made in endosperm mitosis of plants $(1,2)$ led to the opinion that the epinuclear material might be similar, if not identical, to Bajer's clear zone material.

Unpublished observation by Virkki of the spermatocytes I of Oedionychus and related genera revealed a structure of nuclear envelope and epinuclear material different from Omophoita. The Puerto Rican representatives of these genera are now submitted to a new comparison, using preparation methods common for electron microscopy. A similar study emphasizing the ultrastructures will be published elsewhere (13).

\section{MATERIAL AND METHODS}

Omophoita cyanipennis F. and Oedionychus bicolor L. specimens were collected on March 11th, 1975, in the Puerto Rican localities Playa de Salinas and Vacía Talega, respectively. Testes were transported to New Brunswick, N.J., U.S.A., in chilled $1.5 \%$ glutaraldehyde made in $0.1 \mathrm{M}$ cacodylate buffer. The fixation was thus prolonged to about $20 \mathrm{~h}$, which may have caused some swelling of mitochondria. Postfixation was in chilled $2 \% \mathrm{OsO}_{4}$. Luft's modified Epon mixture was used for embedding. Thick sections were stained in Giemsa, thin sections in uranylmagnesiumacetate and lead citrate.

For cellular measurements, some living preparations were made, using Forer's (5) technique. Nuclear and cellular diameters of full grown spermatocyte I were determined, using an ocular micrometer calibrated with an objective micrometer. Each measure is a mean of the shortest and longest diameter. Ten cells were thus measured in both species. Approximate surface and volume values were calculated from the mean diameters of the ten cells (table 1 ).

TABLE 1. Some characteristics of full-grown spermatocyte I in Omophoita cyanipennis and Oedionychus bicolor

\begin{tabular}{lcc}
\hline & Omophoita cyanipennis & Oedionychus bicolor \\
\hline Cell diameter & $43.12 \pm 0.64 \mu \mathrm{m}$ & $53.52 \pm 1.04 \mu \mathrm{m}$ \\
Nuclear diameter & $26.56 \pm 0.48 \mu \mathrm{m}$ & $32.96 \pm 0.72 \mu \mathrm{m}$ \\
Nuclear surface & $2222 \mu^{2}$ & $3420 \mu^{2}$ \\
Nuclear volume & $9843 \mu$ & $18800 \mu \mathrm{m}^{3}$ \\
NSCs per nucleus & - & 220 \\
\hline
\end{tabular}




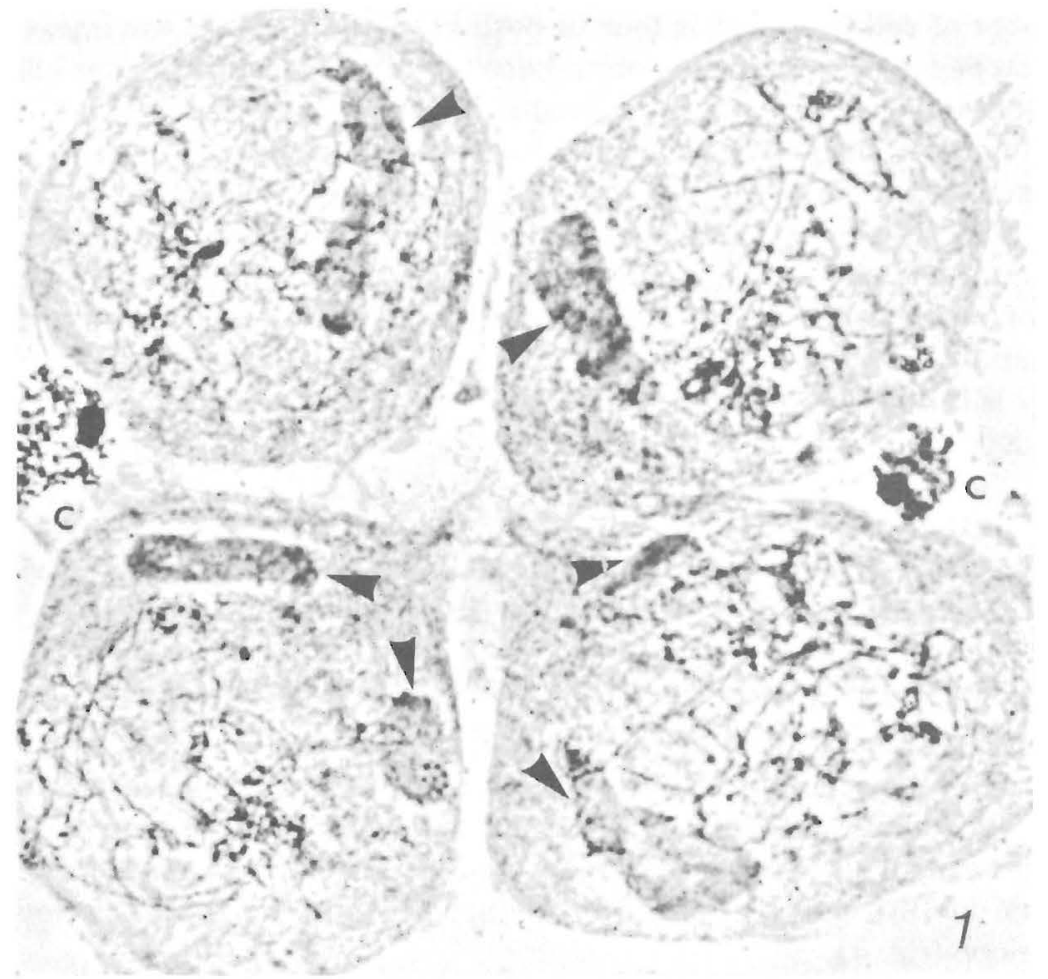

FIG. 1.-Omophoita superba Weise. Pachytene. Four fusomally interconnected spermatocytes I form the entire contents of cyst. Displacement of idiosome (arrowheads) has begun; in the lower two cells, the idiosome has divided in two. Large sex chromosomes fill the top portions of the bouquets. $c=$ cyst cell nucleus. Phase contrast photo from a squash preparation made from a specimen fixed with aceto-alcohol (1:3) June 19th, 1964, in Belém-do-pará, Brazil. $2000 \times$.

Squash preparations made earlier from several South American species were compared with the above species.

Zeiss ${ }^{3}$ Photomicroscope II and JEM-120 electron microscope served for observations and photography.

\section{OBSERVATIONS}

Oedionychina are characterized by a highly diffuse diplotene and a notable second (diplotenic) growth of the spermatocyte I. Prediplotene spermatocytes are not easily recognized from the last spermatogonia: the

${ }^{3}$ Trade names are used inthis publication solely for the purpose of providing specific information. Mention of a trade name does not constitute a guarantee or warranty of equipment or mateials by the Agricultural Experiment Station of the University of Puerto Rico or an endorsement over other equipment or materials not mentioned. 
number of cells per cyst is four in both cases, and the classic images of leptotene and pachytene are often hard to find. The cells in figure 1 show exceptionally clear pachytene bouquets; usually no bivalents, not even the large sex chromosomes, can be individually traced.

Each early spermatocyte I has a dark, seemingly vacuolized cytoplasmic body adjacent to nucleus. Earlier observations on fixed and living preparations showed that this body is situated at the basal (fusomal) region of the cell and includes mitochondria, centrosome(s), and gelated material, probably tubulin (11). Following Smith and Virkki (7), the body is called here idiosome. Already at the end of pachytene, it may be divided in two.

\section{OMOPHOITA CYANIPENNIS}

The postpachytene prophase of spermatocyte I can be roughly divided into six stages that may, however, overlap in different aspects.

Stage 1: Displacement of idiosomal components (figs. 2 and 3)

Observations of living, Janus-green stained preparations show that swarms of mitochondria leave the idiosome when the prophase progresses (11). The same is seen here. The main body of the idiosome does not disintegrate this way, but flattens against the nuclear envelope, may divide in two or three, and even detach temporarily from the nuclear envelope (fig. 4).

Stage 2: Formation of nucleolus and epinuclear material (figs. 3 and 4)

First, a chain or a swarm of small nucleoli appears. Later they coalesce to form 1 to 3 solid, rounded nucleoli that tend to persist until A I (11). A layer of dark epinuclear material starts forming. First it is hard to say whether it is derived from the idiosome or whether it is newly synthesized, but the final thickness of the practically continuous layer points to the latter alternative.

\section{Stage 3: Mature spermatocyte I (fig. 5)}

Cellular and nuclear diameters are approximately $43 \mu \mathrm{m}$ and $26 \mu \mathrm{m}$ (table 1). A layer of epinuclear material about $2.5 \mu \mathrm{m}$ thick surrounds the nucleus. The idiosomal component of the layer is not more recognizable. Electron microscopy (13) shows that cytoplasmic patches and inclusions are very common within the layer. They are practically free of mitochondria, because intrusion of the nascent epinuclear material has preceded release of mitochondria from the idiosome. Although mitochondria are now distributed all over the unlocked cytoplasm, the distribution may still be uneven. 

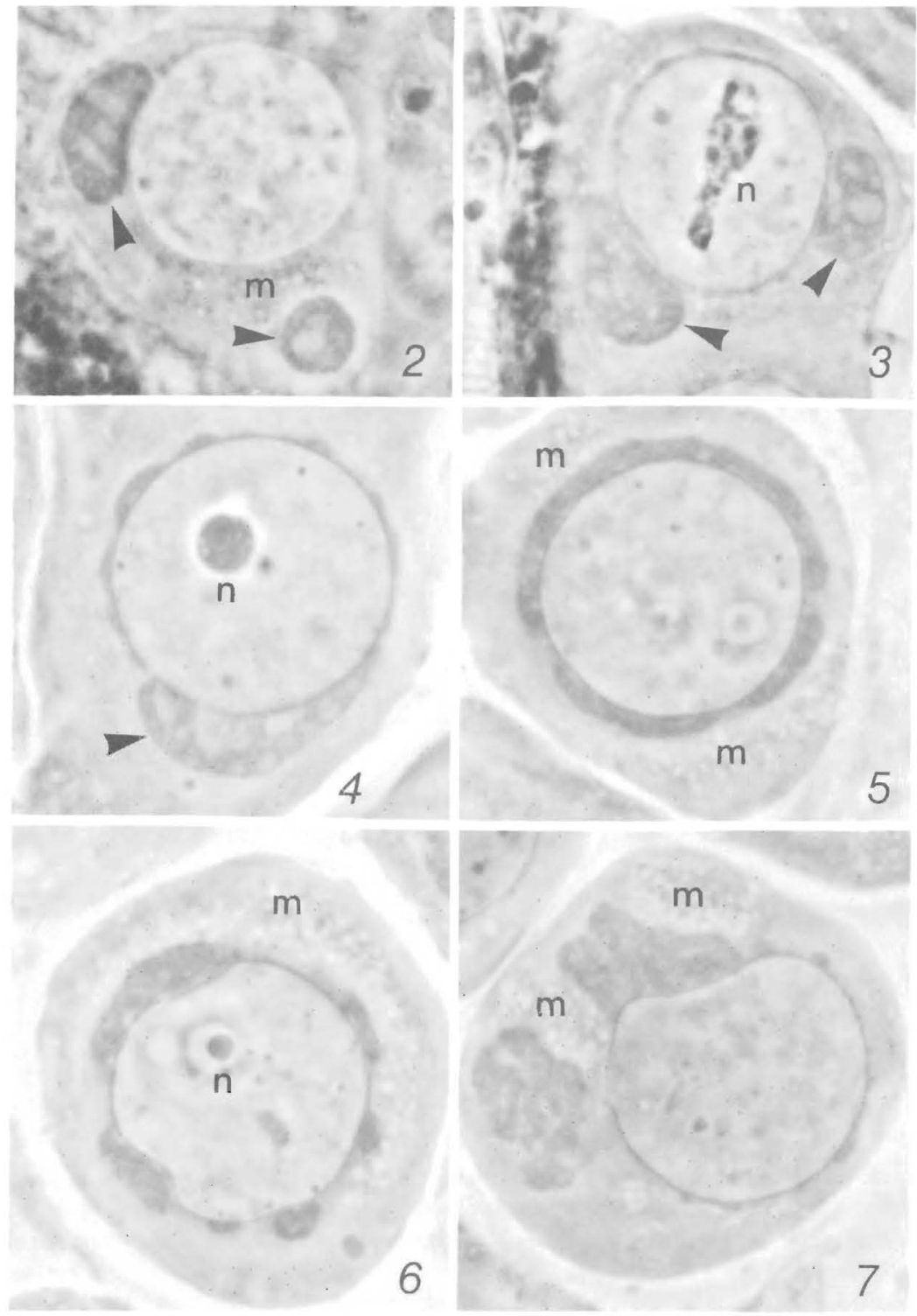

Figs. 2 to 7.-Omophoita cyanipennis. Arrowheads: dark material from idiosome; $\mathrm{m}=$ mitochondria, $\mathrm{n}=$ nucleolus. 2 . Displacement and division of idiosome. 3 . The same, plus formation of a swarm of nucleoli. 4. Coalescence of the nucleoli, and incorporation of idiosomal material to the nascent epinuclear material. 5. Fully grown spermatocyte I with a practically continuous epinuclear material. 6. Beginning nuclear undulation, and accumulation of epinuclear material to aggregates. 7. Nuclear displacement and undulation; accumulation of mitochondria and epinuclear aggregates to the opposite end of the cell. Thick sections, $1280 \times$. 


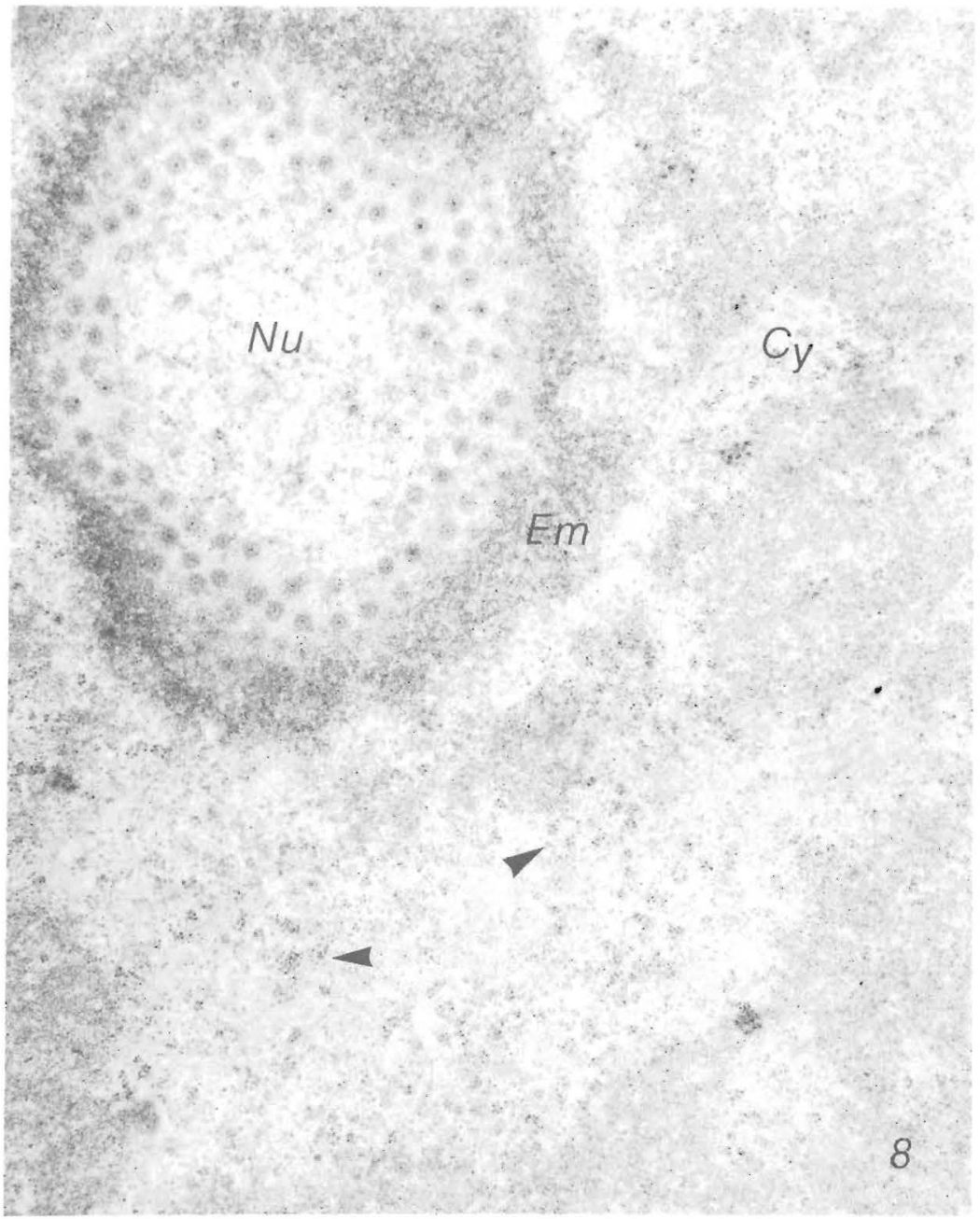

FIG. 8.-Omophoita cyanipennis. A section tangential to nuclear envelope of growing spermatocyte I, showing nuclear pore complexes with a central plug in most of them, epinuclear material (Em), and polyribosomal aggregates (arrowheads). $\mathrm{Nu}=$ nuclear side, $\mathrm{Cy}=$ cytoplasmic side. Thin section, $19600 \times$.

Nuclear pore complexes seem to be randomly distributed, the density being about $38 / \mu \mathrm{m}^{2}$ (fig. 8 ).

Stage 4: Nuclear movements and aggregation of epinuclear material (figs. 6 and 7)

A slight undulation of nuclear envelope, and accumulation of epinuclear material to several aggregates begin simultaneously. Then the 
aggregates become detached from the envelope and concentrate, together with mitochondria, at one end of the cell. The nucleus thus becomes displaced to the opposite end of the cell and suffers from an increasing undulation and deformation at its median side.

Stage 5: Contraction stage (figs. 9 to 11)

In a rapid process (half an hour approximately), the nucleus collapses and its contents become clumped against the cell wall. The mitochondria seem to follow the receding median wall of the nucleus, but the epinuclear material is disintegrated into shreds that soon disappear. During the collapsing process, the nuclear envelope seems to retain its integrity; probably it is broken only at a few places from where the
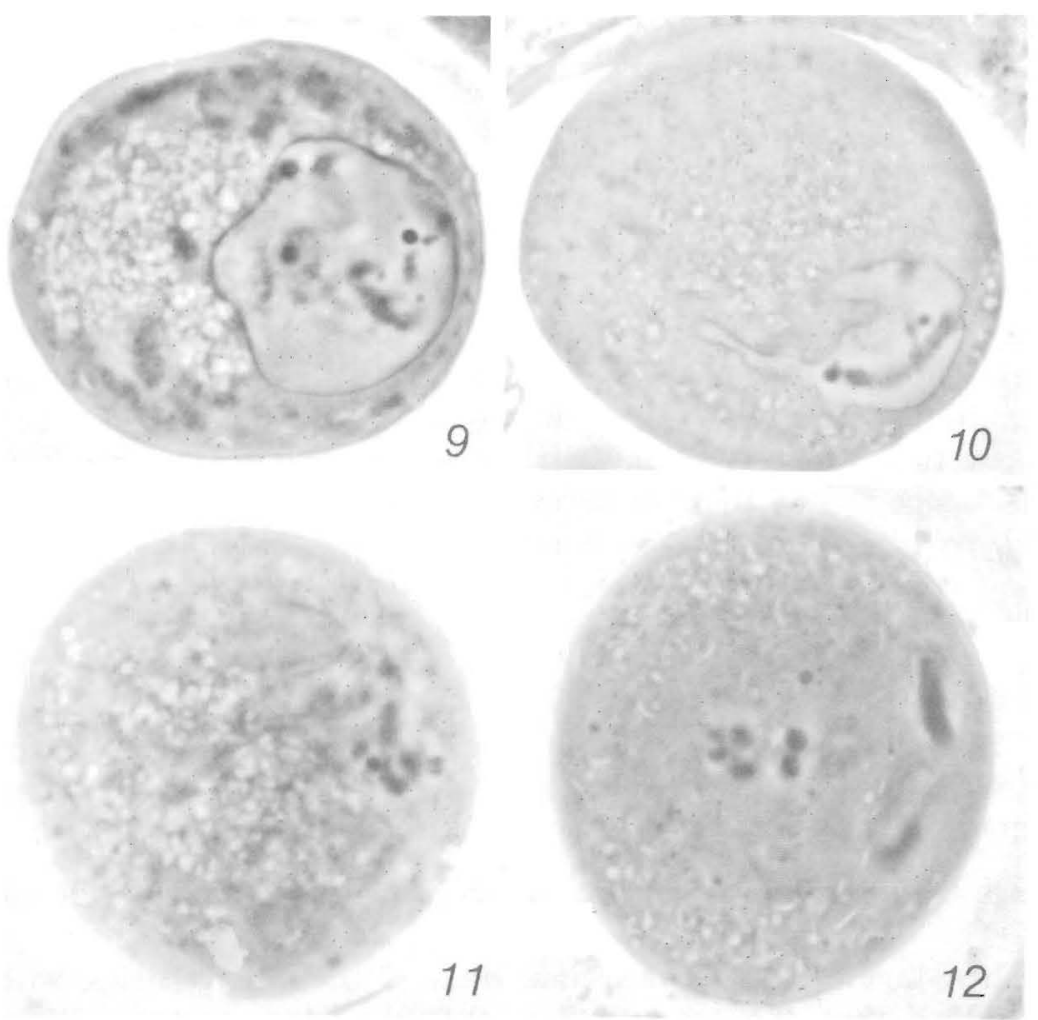

Figs. 9 to 12.-Omophoita cyanipennis. 9. Disintegration of epinuclear material (dark shreds in cytoplasm), and beginning of nuclear shrinkage. Mitochondria appear as whitish bubbles in this series of photographs. 10. Far-advanced nuclear shrinkage; epinuclear material almost out of sight. 11. Full contraction stage. Nuclear envelope extremely folded and probably broken at multiple sites. 12. M I. Distance sex bivalent to the right. Thick sections, $1170 \times$. 
karyolymph flows out. Still at the full contraction (fig. 11), large extensions of the envelope can be seen unbroken, although extremely folded. In this species, condensation of chromosomes proceeds notably during this stage.

Stage 6: Congression

After about one hour (11), the chromosomes leave the clump, the autosomal bivalents shifting to the center of the cell, the large sex chromosomes forming a distance bivalent at the clump site.

At full M I (fig. 12), the autosomal bivalents lay in a centrally located equatorial plate, whereas the sexual distance bivalent lies in a separate, lateral portion ("sex spindle") of the same spindle.

No interkinetic nucleus is formed.

OEDIONYCHUS BICOLOR

\section{Stages 1 and 2}

These stages can hardly be delimited in this species, because formation of nucleolus and of epinuclear material seems to start earlier here. Incorporation of the idiosomal dark material to epinuclear material is similar, as in Omophoita, but from the beginning, the layer remains discontinuous and more irregular in thickness (figs. 13 to 15). This irregularity attains grotesque forms at the end of the stage, when distinct, dark "cups" line the nuclear side of the aggregates of epinuclear material (fig. 16). In light microscope, it cannot be decided whether the cups belong to the epinuclear material or to the nuclear envelope. Electron microscope reveals them as invaginations of the nuclear envelope, filled with polyribosomal aggregates associated with nuclear pore complexes (fig. 20). These unique devices, called nuclear sieve complexes (NSC) (13), are engaged in synthesis of the proteinous epinuclear material.

Stage 3: Mature spermatocyte (fig. 17)

The NSCs remain at the nuclear envelope, retaining some of the epinuclear material in them. Most of the latter leaves the envelope, and aggregates of it can be seen floating freely in the cytoplasm.

Stage 4: Nuclear movements and aggregation of epinuclear material (fig. 18)

This stage resembles the same stage of the other species, with the difference that the aggregates of the epinuclear material disappear earlier, also from the NSCs.

Stage 5: Contraction stage

Most of the NSCs follow the folding nuclear envelope, although some may stay behind (fig. 19). 

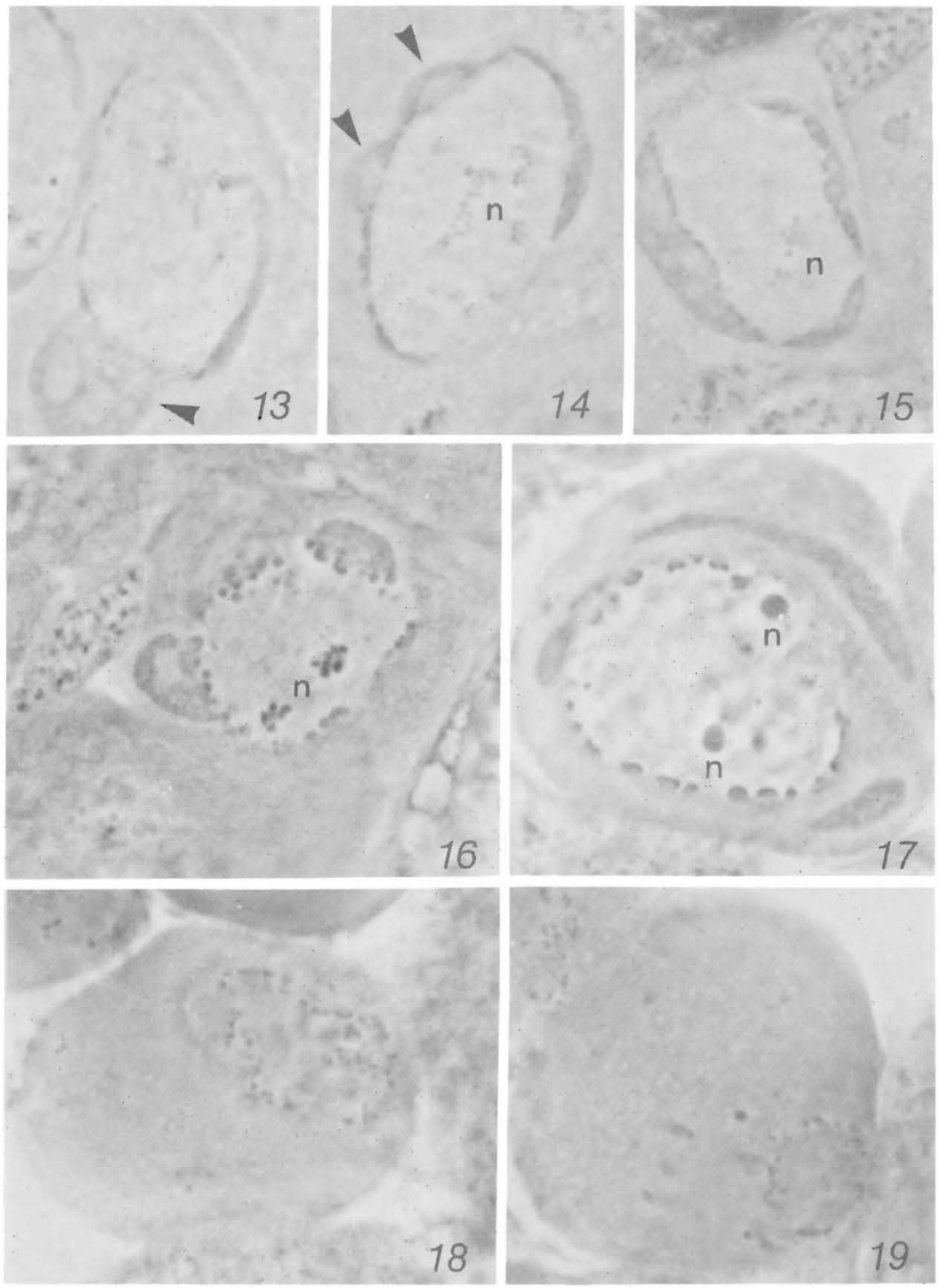

Figs. 13. to 19.-Oedionychus bicolor. 13. Beginning of formation of epinuclear material, and incorporation of the idiosomal dark material (arrowheads) to it. 14. Formation of nucleolar droplet chains (n). Epinuclear material of idiosomal origin (arrowheads) still recognizable. 15. Appearing of dark nuclear sieve complexes (NSC) between nucleus and epinuclear material. Coalescence of nucleolar droplets (n). 16. Cup-like NSCs at the height of their synthetic activity. One cluster of NSCs produces one aggregate of epinuclear material. 17. Fully grown spermatocyte I. Epinuclear material detached from nuclear envelope, except at NSCs. Rounded nucleoli ( $n$ ) formed by coalescence of former droplets. 18. Beginning of the contraction stage. NSCs follow the shrinking nuclear envelope. 19. Full contraction stage. Some NSCs have been left back in cytoplasm, which indicates a partial rupture of the nuclear envelope. Thick sections, $1100 \times$. 
Stage 6: Congression (fig. 21)

A swarm of somewhat lengthened, empty NSCs becomes oriented at a limited area of the spindle surface. In this species, the condensation of chromosomes starts later and remains less conspicuous than in $O$. cyanipennis, a trend seen also in living spermatocytes (11).

At full M I, a lengthy swarm of empty NSCs can be still seen surrounding the spindle (fig. 22). As no interkinetic nucleus is formed, the NSCs are obviously no longer needed. In the spindles of M II, bodies resembling them still are sometimes seen.

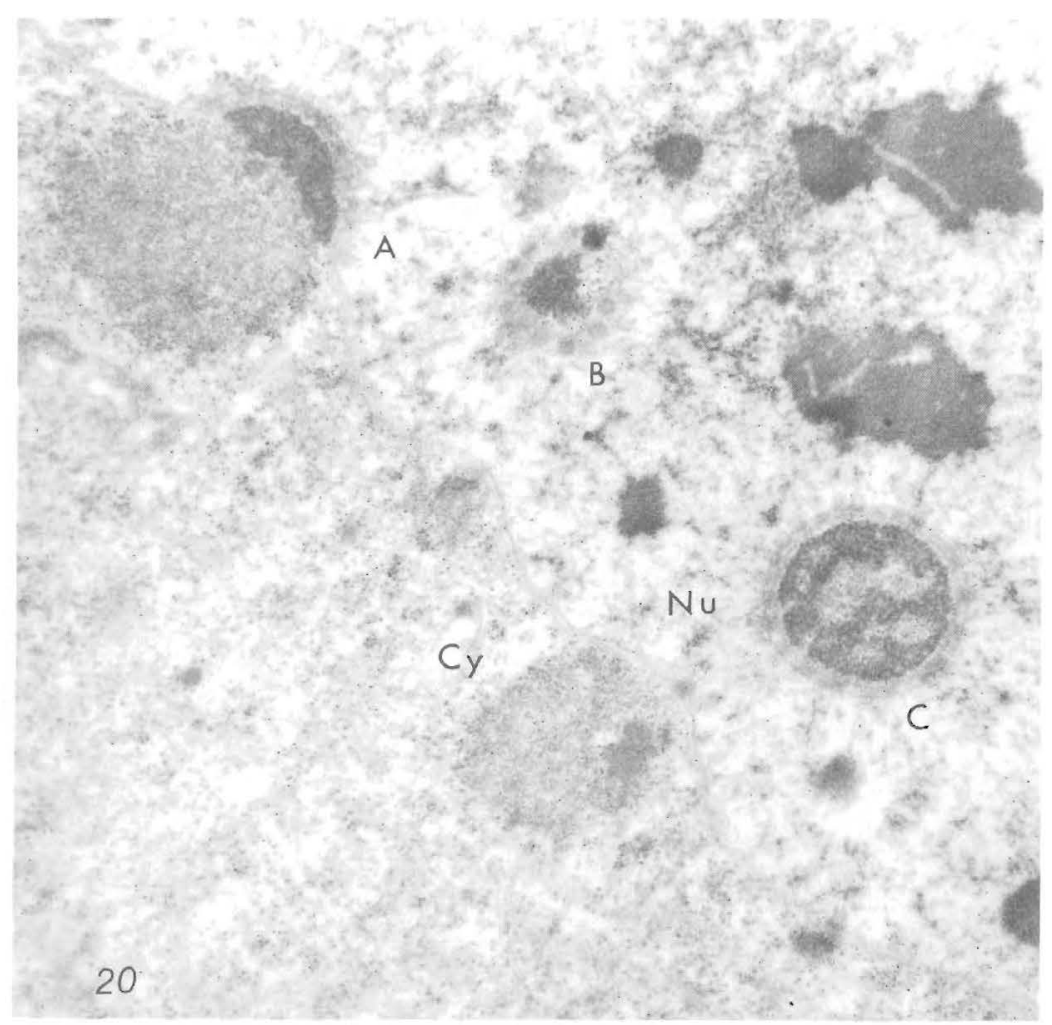

FIG. 20.-Oedionychus bicolor.-Fully grown spermatocyte I (cf. fig. 17). Nuclear envelope runs from the left top corner to the right lower corner, leaving cytoplasmic side $(\mathrm{Cy})$ to the left, nuclear side $(\mathrm{Nu})$ to the right. A to $\mathrm{C}$ mark sections of NSCs. A. A profile showing the shallow invagination of envelope and dark polyribosomal mass filling the "cup" thus arisen. A cloud of epinuclear material extends toward the cytoplasm. The thickened envelope at the sieves seems to be sectioned, due to tightly packed nuclear pore complexes (see C for the same effect). B. A NSC cut near its top, showing some nuclear pore complexes in a tangential view. C. A NSC cut near its mouth. Note the fibrillar (chromosomal?) material connected with nuclear pore complexes here and in A. Two dark masses in the right top corner are sections of chromosomes. Thin section, $16500 \times$. 
Assuming that sections tangential to nuclear envelope show about $1 / 4$ of the entire surface, the number of the NSCs of a mature spermatocyte I can be estimated as about 220 per nucleus. Their size varies considerably. Clustering of NSCs is often recognizable (fig. 23). One such cluster forms one major aggregate of epinuclear material (cf. fig. 16). The spermatocyte I is notably larger than in Omophoita (table 1).

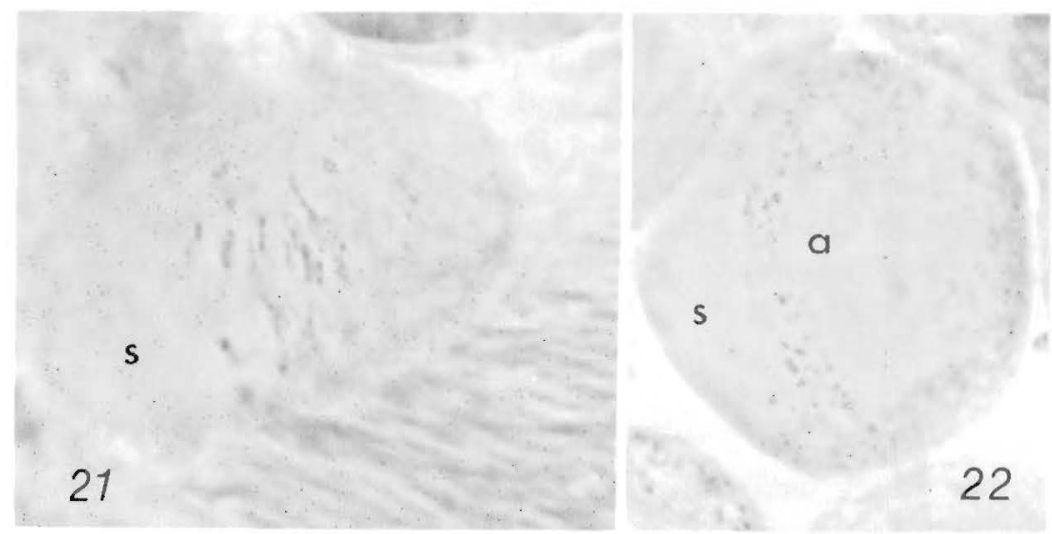

Figs. 21 and 22.-Oedionychus bicolor. Prometaphase and metaphase I, respectively. Empty, abandoned NSCs orientate and swarm around the spindle. a = autosomal portion of the spindle, $s=$ "sex spindle." Thick sections. $1150 \times$.

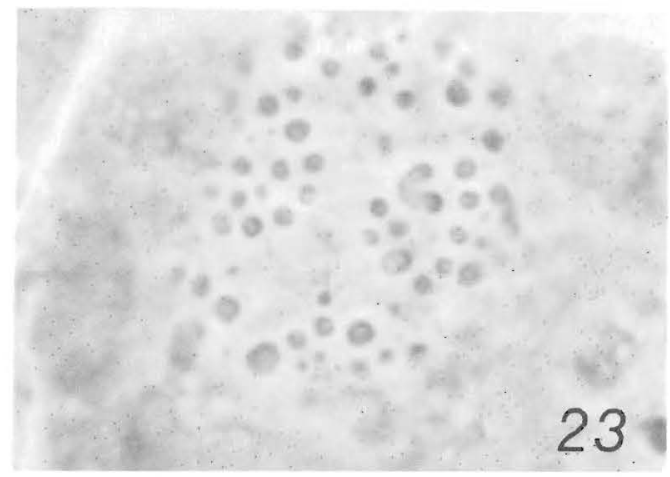

FIG. 23.-Oedionychus bicolor. Fully grown spermatocyte I showing clustering of NSCs (cf. Fig. 16 for profiles of such clusters). Thick section, $1400 \times$.

\section{OTHER SPECIES}

Although identification of NSCs is now perfectly possible at light microscope level, its success depends much on the method used. Living spermatocytes in saline or haemolymph are fairly good, glutaraldehyde plus $\mathrm{OsO}_{4}$-fixed sections are still better. Squashes following aceto- 
alcohol fixation are poor. Specimens fixed in this way were the only ones available for comparison. In all events, it seems safe to say that all Omophoita taxons checked (aequoatorialis Harold, aequinoctialis L., albicollis F., clerica Erichson, cyanipennis octomaculata Crotch, lunata F., quadrinotata quadrinotata F., and superba Weise) have the same envelope structure as $O$. cyanipennis. Also, all Alagoasa taxons checked (dipus Ill., dissepta cyanofasciata Jacoby, mella commutata Bech. \& Bech., postigalis Kirsch, trifasciata F, trifasciata trifasciata F., trifasciata vulgatissima Bech.) have distinct NSCs, and so have two Capraita species, egleri Bech. and trinidadensis Bech. Walterianella, represented by species eugenia Bech., humilis Ill., and ophthalmica Harold, might also be a regular NSC former, but Asphaera spp. (abdominalis Chevr., limitata Harold, octopunctata Jacoby, pauperata Harold, and weyrauchi Bech.) and Pedema umbratica Oliv, seem to stand somewhere between Omophoita and Oedionychus.

\section{DISCUSSION}

\section{CONTRACTION STAGE: AN AMENDMENT}

Present thick section preparations, much superior to acetic acid-fixed or living preparations for observing interior structure of spermatocytes, generally confirm the earlier observations (11), but call for a revision as to the contraction stage. It now appears that the shrinking nuclear envelope remains largely unbroken until the end of the stage. The epinuclear material vanishes in the cytoplasm and does not invade the nuclear space, as believed before. Nuclear undulation and shrinkage, with all the chromosomal contents, against the cell wall, seems to be due solely to microtubular action of the two asters that still remain at the same side of the cell.

\section{NSC IN RELATION TO EVOLUTION}

In the system of Bechyné and Springlová de Bechyné (3), the tribe Oedionychini is divided into two subtribes, Oedionychina and Disonychina. The latter, of neotropical origin, has very variable chromosome numbers and sex chromosome systems, whereas the former, of pantropical origin, has almost invariably $10 \mathrm{II}+\mathrm{X}+\mathrm{y}$ (7). Among the neotropical genera of Oedionychina, only Oedionychus has representatives outside the Americas: five species in the Western Mediterranean of the Old World. Oedionychus in the wider sense (including genera Alagoasa, Pedema, and Walterianella) is also the largest subgroup among Oedionychina (4). It has the widest distribution in America: from Argentina (4) to the region of Great Slave Lake in Canada (according to the collection of Biosystematics Research Institute, Canada Department of Agriculture, Ottawa). Such a size and wide range suggest antiquity of 
the genus. But it seems unacceptable that the more simple organization found in Omophoita spermatocytes would be derivative of the NSC system. Also, evidence from karyotypes favors the other way: the multiple asynaptic sex chromosomes of Omophoita clerica (9) and Asphaera daniela (10) connect Oedionychina with similar Disonychina cases (7).

Thus the high degree of speciation and distribution within Oedionychus might be due to a better fitness rather than to antiquity. The organization of the spermatocyte I nuclear envelope might be one expression of it. Undoubtedly, the Oedionychus system is more efficient than the Omophoita system; "factory" vs. "handwork" comes in mind. It is a surprising novelty in a cellular structure known to be rather conservative $(6,8)$.

\section{RESUMEN}

Los alticidos de la sub-tribu Oedionychina se dividen en dos categorías filogenéticas según la estructura de su membrana nuclear doble y del material epinuclear sintetizado en la etapa difusa del espermatocito I. Omophoita muestra una estructura relativamente simple, rodeada por una zona del material epinuclear, mientras que Oedionychus y los géneros aliados muestran una membrana doble provista de complejos de cedazo nucleares (NSC), y de una zona discontinua del material epinuclear. Este último no participa en la disintegración de la membrana doble, la cual es aplastada contra la pared de la célula, pero no desaparece antes de la congresión de los cromosomas. Los cedazos nucleares vacíos y abandonados forman un enjambre alrededor del huso de M I, y sus restos se ven a veces todavía en el huso de M II. El núcleo intercinético no se forma.

La estructura única de la membrana doble de Oedionychus sugiere que este género tiene un status evolucionario más avanzado que Omophoita, un género que aún tiene afinidades cromosómicas con la subtribu vecina de Disonychina.

\section{LITERATURE CITED}

1. Bajer, A., Ciné-micrographic studies in endosperm. IV. The mitotic contraction stage, Exp. Cell Res. 14: 245-56, 1958.

2. - and Molè-Bajer, J., Ciné-micrographic studies in endosperm. II. Chromosıme, cytoplasmic, and Brownian movements, Chromosoma 12: 374-81, 1956.

3. Jechyné .J., and Springlová de Bechyné, B., Evidenz der bisher bekannten Phe rricaArten (Col. Phytophaga, Alticidae), Entom. Tidskr. 87: 142-70, 1966.

4. Blackwelder, R. E., Checklist of Coleopterous insects of Mexico, Central America, the West Indies, and South America, Bull. Smithsonian Inst. U.S. Nat. Mus. 185 Pt. 4: $551-763,1946$.

5. Forer, A., Local reduction of spindle fiber birefringence in living Nephrotoma suturalis spermatocytes induced by ultraviolet microbuam irradiation, J. Cell Biol. 25: 95-117, 1965.

6. Franke, W. W., On the universality of nuclear pore complex structure, Z. Zellforsch. 105: 405-29, 1970.

7. Smith, S. G., and Virkki, N., Animal Cytogenetics: Coleoptera, Edit. B. John. Borntraeger, Berlin (in preparation).

8. Stevens, B. J., and Andre, J., The nuclear envelope. Pp. 837-71 in: Lima-de-Faria 
(Edit.), Handbook of Molecular Cytology, North-Holland Publ. Co., Amsterdam and London, 1508 pp., 1969.

9. Virkki, N., Orientation and segregation of asynaptic multiple sex chromosomes in the male Omophoita clerica Erichson (Coleoptera: Alticidae), Hereditas 57: 275-88, 1967.

10. - Regular segregation of seven asynaptic sex chromosomes in the male of Asphaera daniela Bechyné (Coleoptera, Alticidae), Caryologia 21: 47-51, 1968.

11. Contraction stage and formation of the distance sex bivalent in Oedionychina (Coleoptera, Alticidae), Hereditas 71: 259-88, 1972.

12. - Spermatogonial budding in fleabeetles, Caryologia 26: 405-23, 1973.

13. - and Kimura, M., Extreme clustering of nuclear pores in spermatocytes I of some Oedionychina fleabeetles (in preparation). 